\title{
Molecular detection of Taenia spp. in dogs' feces in Zanjan Province, Northwest of Iran
}

\author{
Mohammad Hasan Kohansal, Abbasali Nourian, Ali Haniloo and Asghar Fazaeli \\ Department of Parasitology and Mycology, School of Medicine, Zanjan University of Medical Sciences, Zanjan, Iran. \\ Corresponding author: Asghar Fazaeli, e-mail: fazaeli@zums.ac.ir, \\ Co-authors: MHK: kohansalhasan@gmail.com, AN: nourian@zums.ac.ir, AH: hani@zums.ac.ir \\ Received: 13-12-2016, Accepted: 14-03-2017, Published online: 23-04-2017
}

doi: 10.14202/vetworld.2017.445-449 How to cite this article: Kohansal MH, Nourian A, Haniloo A, Fazaeli A (2017) Molecular detection of Taenia spp. in dogs' feces in Zanjan Province, Northwest of Iran, Veterinary World, 10(4): 445-449.

\begin{abstract}
Aim: Echinococcus and Taenia spp. are important but neglected zoonotic helminths of dogs. Dogs as the most relevant definitive hosts harbor several species of Taenia and Echinococcus simultaneously in their gastrointestinal lumen which are morphologically indistinguishable. In this study, we used a multiplex polymerase chain reaction (PCR) method to identify Taeniid infections which seem to be highly distributed in the study region.

Materials and Methods: A total of 450 dog fecal samples were collected from eight different areas of Zanjan province, northwest of Iran, and examined using a flotation method followed by multiplex PCR for detection and identification of parasites' eggs.

Results: Gastrointestinal parasites were found in 86 out of 450 fecal samples (19.1\%) by microscopic examination. Taeniid eggs were observed in $5.6 \%$ of samples, containing $0.45 \%, 3.8 \%$, and $1.3 \%$ Echinococcus granulosus, Taenia spp., and mix infection of both E. granulosus and Taenia spp., respectively. Echinococcus multilocularis was absent in the samples.

Conclusion: A relatively low rate of E. granulosus (1.8\%) was observed in this study. However, risks of this parasite should not be overlooked, and control programs need to be extended for this species and other Taeniid spp. In particular, dogs are recommended to be dewormed more frequently.
\end{abstract}

Keywords: dog, Echinococcus spp., eggs, multiplex polymerase chain reaction, Taenia spp.

\section{Introduction}

Dogs as animals that are involved with human life and environment harbor a number of important zoonotic helminth infections some of which are Taeniid cestodes [1,2]. The important species of Taeniidae family presented in dogs include Echinococcus granulosus, Echinococcus multilocularis, Taenia ovis, Taenia multiceps, and Taenia hydatigena. Among these parasites, two major species, E. granulosus and E. multilocularis, are highly important from a medical and public health standpoint [3-5]. There are different ways for parasite transmission; however, the ingestion of infective eggs is the major transmission route for intermediate and aberrant hosts. After accidental ingestion of Echinococcus eggs, it passes through canids feces and is transmitted to the intermediate hosts which finally develop echinococcosis cysts in organs, tissues, or body cavities [6,7].

Canids can pass several species of Taenia and Echinococcus eggs simultaneously. However, they are microscopically indistinguishable, and other methods are required for simple and reliable identification of

Copyright: Kohansal, et al. Open Access. This article is distributed under the terms of the Creative Commons Attribution 4.0 International License (http://creativecommons.org/licenses/ by/4.0/), which permits unrestricted use, distribution, and reproduction in any medium, provided you give appropriate credit to the original author(s) and the source, provide a link to the Creative Commons license, and indicate if changes were made. The Creative Commons Public Domain Dedication waiver (http:// creativecommons.org/publicdomain/zero/1.0/) applies to the data made available in this article, unless otherwise stated. the parasite species for effective diagnosis and treatment, as well as epidemiological survey and control programs [8]. Detection and differentiation of eggs from individual definitive hosts or feces collected in the field are essential challenge because they are sanitary indicators of the exposure level [9]. Despite post-mortem (necropsy) detection is highly sensitive and specific, it is evidently laborious, raises ethical issues, and is risky $[10,11]$. Two alternative approaches based on the detection of the parasitic copro-DNA molecules by polymerase chain reaction (PCR) and copro-antigens by enzyme-linked immunosorbent assay in animal fecal samples have been successfully developed and evaluated $[12,13]$. The detection and identification of copro-DNA may be advantageous over the detection of copro-antigens, as it provides the possibility of post-detection analysis of the sample DNA for precise identification of the proposed species. A number of techniques such as restriction fragment length polymorphism, direct comparison of PCR-amplified DNA sequences, random amplification of polymorphic DNA, single-strand conformation polymorphism, and microsatellite analysis have been employed for the identification of Echinococcus and Taenia spp. [8]. Studies showed that among different PCR methods, multiplex PCR targeting mitochondrial DNA is considered useful for the detection of Taeniid eggs [14]. Availability of the mitochondrial genome information for all Echinococcus species and several Taenia species provide a very rich resource of genetic 
information for molecular identification and discrimination [8]. Previous multiplex PCR studies targeting the mitochondrial DNA successfully amplified the DNA of all cysts and eggs and differentiated between Echinococcus spp., and Taenia spp. $[10,15,16]$. In the study area, northwest of Iran, there was no information regarding the infection rate of Taeniid spp. eggs in dogs' feces dispersed in the environment to evaluate the potential risk of infection in human population living in the area.

The aim of this study was to detect the Taeniid eggs in dispersed feces of stray dogs and to identify different species, including zoonotic E. granulosus and E. multilocularis, and Taenia spp., in Zanjan province, northwest of Iran.

\section{Materials and Methods}

\section{Ethical approval}

The study proposal was reviewed and approved by the Institutional Research Ethics Committee at Zanjan University of Medical Sciences.

\section{Study area}

Zanjan province is situated in the northwest of Iran between latitudes of $36^{\circ} 40^{\prime} 24^{\prime \prime}$ and longitudes of $48^{\circ} 28^{\prime} 43^{\prime \prime}$. It is divided into eight geographical realms with total area of $22164 \mathrm{~km}^{2}$ occupying $1.34 \%$ of Iran territory (Figure-1). Zanjan is one of the coldest provinces of Iran with an average minimum temperature of $-19^{\circ} \mathrm{C}$ that drops to $-27^{\circ} \mathrm{C}$ during the icy days. The average maximum temperature of Zanjan is around $27^{\circ} \mathrm{C}$ and the temperature rises to $32^{\circ} \mathrm{C}$ on hot days. The province is one of the important centers of agriculture and animal husbandry in the west of Iran. The number of livestock in the province is 2.366 .411 animal [17].

\section{Collection and examination of dog fecal samples}

The study was conducted between June and November 2015. A total of 450 samples of dog fresh feces were collected from streets in urban locations as well as farms in rural areas of different parts of the province. The fecal samples were placed in labeled "ziploc" bags and transported to the Research Laboratory at the Department of Parasitology, Faculty of Medicine, Zanjan University of Medical Sciences, on the day of collection and underwent microscopic examinations. All samples were examined with the

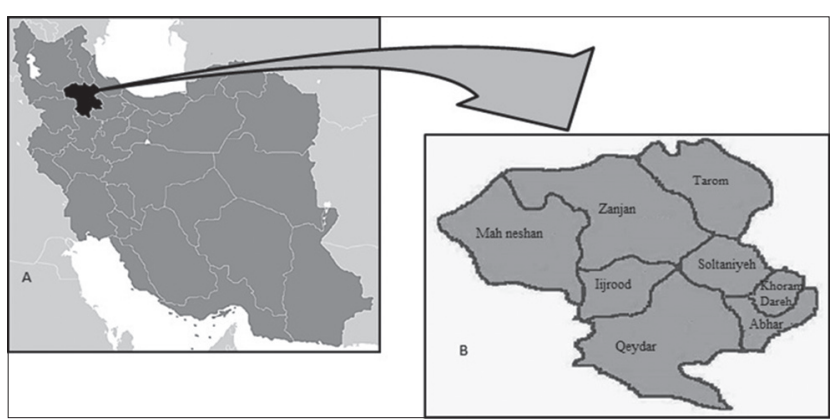

Figure-1: Map of Zanjan province in Iran and its regions, where dog fecal samples were collected. naked eye for possible observation of adult helminths and proglottids of cestodes, followed by microscopic examination using formalin-ethyl acetate sedimentation concentration method. Consequently, to isolate Taeniid eggs, samples were frozen at $-80^{\circ} \mathrm{C}$ for at least 3 days for safety reasons and then zinc chloride solution (specific density $1.45 \mathrm{~g} / \mathrm{ml}$ ) method was used as previously described [18]. Floated samples were passed through gauze and were centrifuged. The sediments were stored at $-20^{\circ} \mathrm{C}$ until use.

\section{DNA extraction and multiplex PCR}

The DNA of positive samples with Taenia spp. eggs was extracted using the QIAamp fast DNA stool Mini kit (Qiagen, Germany) according to the manufacturer's protocol with slight modifications. First, $600 \mu 1$ digestion buffer (100 mM NaCL, $10 \mathrm{mM}$ Tris-HCL $\mathrm{pH} 8.0$, and $25 \mathrm{mM}$ EDTA) was mixed with $200 \mu \mathrm{l}$ of each sediment obtained from flotation method. Glass pearls $(0.45-0.52 \mathrm{~mm}$ diameter) were added to the mixtures, and the samples were vortexed for $10 \mathrm{~min}$. Consequently, they were subjected to seven cycles of freeze/thaw using liquid nitrogen and boiling water for disrupting the egg walls. At this stage, $20 \mu 1$ proteinase $\mathrm{K}$ (final concentration of $200 \mu \mathrm{g} / \mathrm{mL}$ ) and $40 \mu 1$ of $2 \%$ sodium dodecyl sulfate were added to each sample and placed in $60^{\circ} \mathrm{C}$ water bath for $16 \mathrm{~h}$. Finally, the parasite DNA was extracted according to the manufacturer's instructions. Concentration of the extracted DNAs was measured by Nanodrop (Thermo scientific 2000C). The extracted DNAs were stored at $-20^{\circ} \mathrm{C}$ until analysis. Primers (targeting mitochondrial DNA), time and thermal conditions, and other parameters for multiplex PCR were used according to Trachsel et al. [14]. The primers used for multiplex PCR in this study are shown in Table-1. The amplification reactions were provided in $50 \mu 1$ volume, containing $25 \mu 1$ Master Mix (Ampliqon, Vietnam), $5 \mu 1$ primers $(2 \mu \mathrm{M}$ of each primer, Cest1, Cest2, Cest3, Cest 4 , and $16 \mu \mathrm{M}$ of primer Cest 5 in $\mathrm{H} 2 \mathrm{O}$ ), $18 \mu 1 \mathrm{H}_{2} \mathrm{O}$, and $2 \mu 1$ templates DNA. PCR cycling conditions consisted of one cycle of 15 min primary denaturation at $95^{\circ} \mathrm{C}$; followed by 40 cycles of denaturing at $94^{\circ} \mathrm{C}$ for $30 \mathrm{~s}$, annealing at $58^{\circ} \mathrm{C}$ for $90 \mathrm{~s}$, and extension at $72^{\circ} \mathrm{C}$ for $10 \mathrm{~s}$, ended with one cycle of final extension at $72^{\circ} \mathrm{C}$ for $7 \mathrm{~min}$. Finally, $5 \mu \mathrm{l}$ of each PCR product were analyzed by electrophoresis on $2 \%$ agarose gel stained with Safe Stain (SinaClon, Iran). A 100 bp ladder as molecular size marker was run together with samples to determine the fragment lengths. PCR products were visualized under ultraviolet light (UVIdoc, England).

\section{Results}

A total of 86 out of 450 examined fecal samples $(19.1 \%)$ contained at least one gastrointestinal parasite. Taeniid eggs were observed in 25 samples (Figure-2). They were subjected to multiplex PCR analysis. Amplification of a 117 bp fragment of $\mathrm{rrnS}$ 
Table-1: Primers, targets, and sequences applied for multiplex PCR.

\begin{tabular}{|c|c|c|c|c|}
\hline Target species & $\begin{array}{l}\text { Target } \\
\text { gene }\end{array}$ & $\begin{array}{l}\text { Primer } \\
\text { designation }\end{array}$ & Sequences $\left(5^{\prime}-3^{\prime}\right)$ & Amplicon size (bp) \\
\hline \multirow[t]{2}{*}{ Echinococcus multilocularis } & nad1 & Cest1 & TGCTGATTTGTTAAAGTTAGTGATC & 395 \\
\hline & & Cest2 & CATAAATCAATGGAAACAACAACAAG & \\
\hline \multirow[t]{2}{*}{ Echinococcus granulosus } & rrnS & Cest4 & GTIITGTGTGTTACATTAATAAGGGTG & 117 \\
\hline & & Cest5 & GCGGTGTGTACMTGAGCTAAAC & \\
\hline \multirow[t]{2}{*}{ Taenia sp. } & rrnS & Cest3 & YGAYTCTIITTAGGGGAAGGTGTG & 267 \\
\hline & & Cest5 & GCGGTGTGTACMTGAGCTAAAC & \\
\hline
\end{tabular}

$\mathrm{PCR}=$ Polymerase chain reaction

target was observed in $0.45 \%(\mathrm{n}=2)$ of the fecal samples, indicative of infection with E. granulosus eggs. A $267 \mathrm{bp}$ fragment, indicative of Taenia spp. infection, was amplified in $3.8 \%(n=17)$ of the samples (Figure-3). There was no amplification of the $395 \mathrm{bp}$ fragment of nad1 target in the 25 microscopically positive fecal samples, confirming no infection with E. multilocularis. In addition, 6 dog samples (1.3\%) were coinfected with E. granulosus and other Taenia spp. (Figure-4).

\section{Discussion}

The results of this study showed a relatively high rate of parasitic infection in dog feces dispersed in the environment of the study region in northwest of Iran, consisting of several parasite species, including Echinococcus and Taenia spp. Gastrointestinal parasites of dogs are of great importance because of the potential risk of transmission of zoonotic species to human in both rural and urban areas. Transmission of dog-related zoonotic parasites to humans primarily takes place through contact with the feces of the infected animals [1]. Information about the prevalence of such parasitic infections in dog fecal sources can be taken to control measure to minimize the risk of their transmission to humans. In this study, the overall prevalence of parasites was $19.1 \%$ among the 450 fecal samples analyzed. This infection rate was greater than what reported in China (12\%) [19] and Kyrgyzstan (18\%) [20], but less than that of Argentina (37.86 \%) [21] and Spain (28\%) [22]. Among parasites detected by flotation method, Taeniid eggs were observed in $5.6 \%$ samples which was less than the infection rate reported by Rahimi et al. [16] in Mazandaran, north of Iran. The cestode family of Taeniidae contains 2 genera, Taenia and Echinococcus, which are closely related to each other, and their zoonotic importance made them the subject of intensive epidemiological studies [23]. The accurate diagnosis of Taeniid eggs provides key information to control the diseases. Stool exam is not accurate enough for epidemiological purposes, because the Taeniidae spp. eggs are extremely similar. Likewise, immunological methods (for copro-antigens detection) and serum antibodies are not sufficiently specific to differentiate these pathogens at species level [24]. To overcome these limitations, various molecular approaches, such as high-sensitivity Multiplex PCR

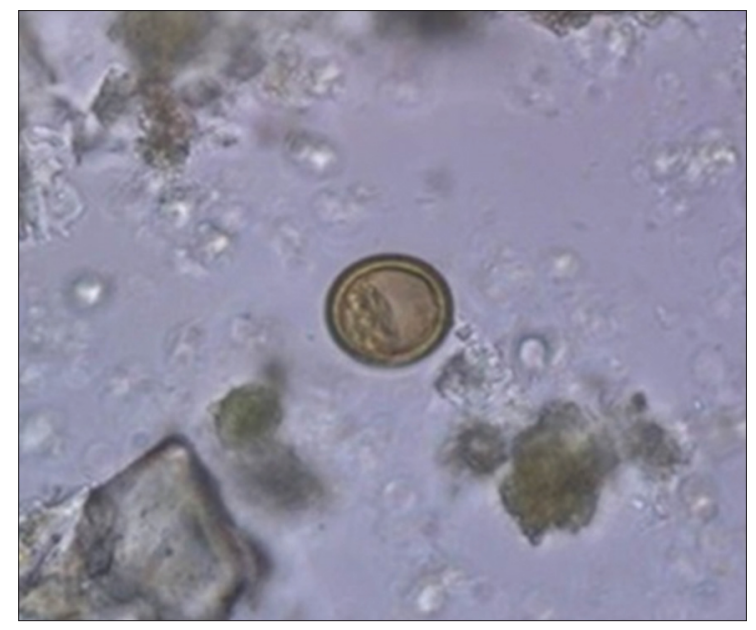

Figure-2: Taenia/Echinococcus eggs detected in dog fecal samples.

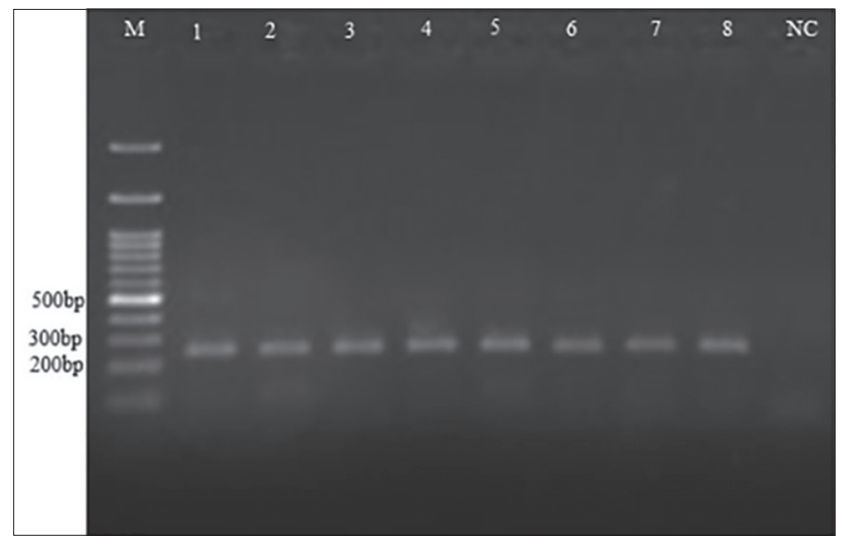

Figure-3: Gel electrophoresis of the polymerase chain reaction (PCR) products of Taenia spp. detected in dog feces. $M$ is the $100 \mathrm{bp}$ ladder. Lanes 1 to 8 are $267 \mathrm{bp}$ PCR products representative of Taenia spp. NC is negative control.

technique, have been developed $[14,16]$. The results of multiplex PCR in our study showed a $0.45 \%$ infection rate with E. granulosus, $3.8 \%$ with Taenia spp., and $1.3 \%$ coinfection of E. granulosus and Taenia. In total, $1.8 \%$ of the examined samples were infected with important zoonotic species of $E$. granulosus in Zanjan province. In the studies performed in other areas of Iran, different infection rates of these species were reported using multiplex PCR technique. Mobedi et al. [25] and Beiramvand et al. [26] reported the rate of these infections as $23.7 \%$ and $26.3 \%$, respectively. However, in another study conducted by 


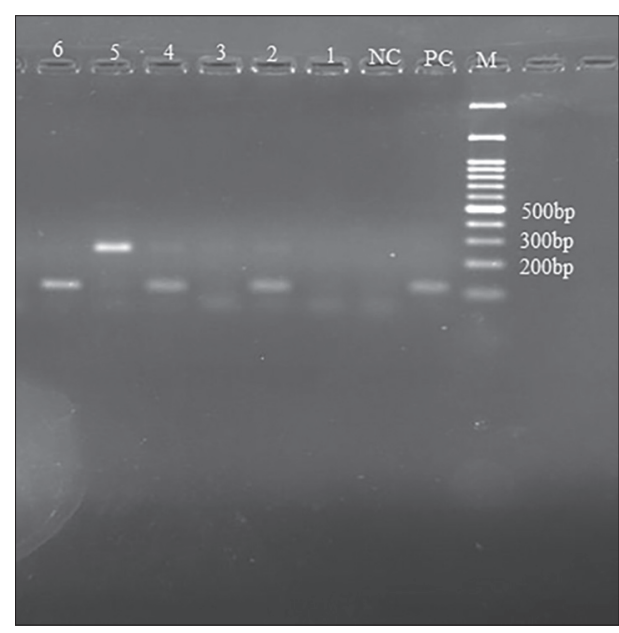

Figure-4: Gel electrophoresis of the polymerase chain reaction (PCR) products of mix infections with Taenia spp., and Echinococcus granulosus in dog feces. $\mathrm{M}$ is the $100 \mathrm{bp}$ ladder. PC is positive control for $E$. granulosus (G1). NC is negative control. Lanes 1 to 6 are 267 bp and 117 PCR products of the samples.

Gholami et al. [27], no positive sample was found in stray dogs in northern part of Iran. There are several environmental and socioecological factors that are involved in the circulation of E. granulosus between hosts and can affect the prevalence of the infection. These include extensive sheep farming, home slaughter and dog feeding with animal viscera, dogs scavenging on infected carcasses, and improper disposal of carcasses [28]. Echinococcosis is endemic in Iran, and there are many reports from various parts of the country [29]. The prevalence rate of cystic echinococcosis has previously been reported in human population [30]. It was estimated that approximately $1 \%$ of admissions to surgical wards were related to cystic echinococcosis [31,32]. E. multilocularis is another parasite that can be found in dogs. In humans, the larval stage of E. multilocularis causes alveolar echinococcosis (AE), a space-occupying lesion, which is lethal if untreated. AE, as a sporadic human disease, has been distributed over the most of the northern hemisphere and some countries of the Middle East [7]. In Iran, a few studies were conducted on E. multilocularis infection [26,33]; however, no study with this concern has been performed in Zanjan province. In this study, no $395 \mathrm{bp}$ amplicon, representative of E. multilocularis eggs, was observed in the Taeniidpositive fecal samples of dogs. Our result is in line with a couple of studies performed in north of Iran, in which no E. multilocularis was detected in dog fecal samples $[16,25]$. Studies have shown that median estimate of the total numbers of AE cases in the world is 18,235 per year [34]. It should be noted that this species usually has a sylvatic life cycle, involving foxes rather than dogs as the definitive host $[6,35]$. In spite of no detection of E. multilocularis in this study, it cannot be claimed that this infection is completely absent in the area, and larger scale studies focusing on other hosts (definitive and intermediate) are needed.
Al-Sabi et al. [10] developed a multiplex-PCR to differentiate Taenia species in rodents and carnivores. Compared to morphological methods, their assay had a significantly higher sensitivity as they identified 31 of 32 Taenia metacestodes from rodents, whereas only 14 samples were specifically identified by morphological methods. Yamasaki et al. [15] devised a multiplex PCR for differential diagnosis of taeniasis and cysticercosis of humans. They successfully amplified 827 and 269 bp products for T. saginata and Asian Taenia, respectively, using mixed species- or genotype-specific primer sets.

\section{Conclusion}

It was confirmed that the Taeniid infections are endemic in dogs in Zanjan province, northwest of Iran. Dog feces dispersed in the environment, particularly those of stray dogs, are an important source of transmissible infection to ruminants as intermediate hosts and human as an accidental host. Among these, E. granulosus eggs, which are the cause of a considerable number of human cystic hydatidosis, are of greater importance. Differences between infection rates of this parasite in different parts of Iran depend on many factors such as definitive and intermediate hosts. Therefore, more studies are required to determine precise prevalence of these parasites in all hosts in different areas around the study regions.

\section{Authors' Contributions}

MHK provided the research proposal, collected the samples and performed laboratory works. AN and $\mathrm{AF}$ supervised the project. AH was a scientific and lab diagnostic advisor to the project. The manuscript was written by MHK, finally revised by AF. All authors read and approved the final manuscript.

\section{Acknowledgments}

This article is a part of $\mathrm{PhD}$ thesis done by M. H. Kohansal. The study was financially supported by Deputy for Research at Zanjan University of Medical Sciences and Health Services (Grant No. A-12-153-8).

\section{Competing Interests}

The authors declare that they have no competing interests.

\section{References}

1. Robertson, I.D. and Thompson, R. (2002) Enteric parasitic zoonoses of domesticated dogs and cats. Microbes Infect., 4(8): 867-873.

2. Chomel, B.B. (2014) Emerging and re-emerging zoonoses of dogs and cats. Animals, 4(3): 434-445.

3. Cardona, G.A. and Carmena, D. (2013) A review of the global prevalence, molecular epidemiology and economics of cystic echinococcosis in production animals. Vet. Parasitol., 192(1): 10-32.

4. Deplazes, P. and Eckert, J. (2001) Veterinary aspects of alveolar echinococcosis-a zoonosis of public health significance. Vet. Parasitol., 98(1): 65-87.

5. Eckert, J. and Deplazes, P. (2004) Biological, epidemiological, and clinical aspects of echinococcosis, a zoonosis of 
increasing concern. Clin. Microbiol. Rev., 17(1): 107-135.

6. Moro, P. and Schantz, P.M. (2009) Echinococcosis: A review. Int. J. Infect. Dis., 13(2): 125-133.

7. Torgerson, P. and Budke, C. (2003) Echinococcosis-an international public health challenge. Res. Vet. Sci., 74(3): 191-202.

8. McManus, D.P. (2006) Molecular discrimination of taeniid cestodes. Parasitol. Int., 55: S31-S37.

9. Cabrera, M., Canova, S., Rosenzvit, M. and Guarnera, E. (2002) Identification of Echinococcus granulosus eggs. Diagn. Microbiol. Infec. Dis., 44(1): 29-34.

10. Al-Sabi, M.N. and Kapel, C.M. (2011) Multiplex PCR identification of Taenia spp. In rodents and carnivores. Parasitol. Res., 109(5): 1293-1298.

11. Craig, P., Rogan, M. and Campos-Ponce, M. (2003) Echinococcosis: Disease, detection and transmission. Parasitol., 127(S1): 5-20.

12. Huang, Y., Yang, W., Qiu, J., Chen, X., Yang, Y., Qiu, D., Xiao, N., Xiao, Y. and Heath, D. (2007) A modified coproantigen test used for surveillance of Echinococcus spp. In Tibetan dogs. Vet. Parasitol., 149(3): 229-238.

13. Jiang, W., Liu, N., Zhang, G., Renqing, P., Xie, F., Li, T., Wang, Z. and Wang, X. (2012) Specific detection of Echinococcus spp. from the Tibetan fox (Vulpes ferrilata) and the red fox (V. vulpes) using copro-DNA PCR analysis. Parasitol. Res., 111(4): 1531-1539.

14. Trachsel, D., Deplazes, P. and Mathis, A. (2007) Identification of taeniid eggs in the faeces from carnivores based on multiplex PCR using targets in mitochondrial DNA. Parasitol., 134(6): 911-920.

15. Yamasaki, H., Allan, J.C., Sato, M.O., Nakao, M., Sako, Y., Nakaya, K., Qiu, D., Mamuti, W., Craig, P.S. and Ito, A. (2004) DNA differential diagnosis of taeniasis and cysticercosis by multiplex PCR. J. Clin. Microbiol., 42(2): 548-553.

16. Rahimi, M., Sarvi, S., Daryani, A., Sharif, M., Ahmadpour, E., Shokri, A. and Mizani, A. (2016) Application of multiplex PCR for the simultaneous detection of Taenia spp. From domestic dogs in the north of Iran. Helminthologia, 53(3): 285-289.

17. National Mapping Agency. (2016) Zanjan Province. Available from: http://www.ncc.org.ir/homepage.aspx? site $=$ NCCPortal\&tabid $=1 \&$ lang=fa-IR. Accessed on 15-07-2016.

18. Mathis, A., Deplazes, P. and Eckert, J. (1996) An improved test system for PCR-based specific detection of Echinococcus multilocularis eggs. J. Helminthol., 70(3): 219-222.

19. Budke, C.M., Jiamin, Q., Craig, P.S. and Torgerson, P.R. (2005) Modeling the transmission of Echinococcus granulosus and Echinococcus multilocularis in dogs for a high endemic region of the Tibetan plateau. Int. J. Parasitol., 35(2): 163-170.

20. Ziadinov, I., Mathis, A., Trachsel, D., Rysmukhambetova,A., Abdyjaparov, T., Kuttubaev, O., Deplazes, P. and Torgerson, P.R. (2008) Canine echinococcosis in Kyrgyzstan: Using prevalence data adjusted for measurement error to develop transmission dynamics models. Int. J. Parasitol., 38(10): 1179-1190.

21. Soriano, S.V., Pierangeli, N.B., Roccia, I., Bergagna, H.F.J., Lazzarini, L.E., Celescinco, A., Saiz, M.S., Kossman, A., Contreras, P.A., Arias, C. and Basualdo, J.A. (2010) A wide diversity of zoonotic intestinal parasites infects urban and rural dogs in Neuquén, Patagonia, Argentina. Vet. Parasitol., 167(1): 81-85.

22. Miró, G., Mateo, M., Montoya, A., Vela, E. and Calonge, R. (2007) Survey of intestinal parasites in stray dogs in the Madrid area and comparison of the efficacy of three anthelmintics in naturally infected dogs. Parasitol. Res., 100(2): 317-320.

23. Eckert, J., Gemmell, M., Meslin, F. and Pawłowski, Z. (2001) WHO-OIE Manual on Echinococcosis in Humans and Animals: A Public Health Problem of Global Concern. Courtesy of the Institute of Parasitology, University of Zurich. Available from: http://www.oie.int. Accessed on 18-08-2016.

24. Nakao, M., Yanagida, T., Okamoto, M., Knapp, J., Nkouawa, A., Sako, Y. and Ito, A. (2010) State-of-theart Echinococcus and Taenia: Phylogenetic taxonomy of human-pathogenic tapeworms and its application to molecular diagnosis. Infect. Genet. Evol., 10(4): 444-452.

25. Mobedi, I., Zare-Bidaki, M., Siavashi, M., Naddaf, S., Kia, E. and Mahmoudi, M. (2013) Differential detection of Echinococcus Spp. Copro-DNA by Nested-PCR in domestic and wild definitive hosts in Moghan plain, Iran. Iran. $J$. Parasitol., 8(1): 107-113.

26. Beiromvand, M., Akhlaghi, L., Massom, S.H.F., Mobedi, I., Meamar, A.R., Oormazdi, H., Motevalian, A. and Razmjou, E. (2011) Detection of Echinococcus multilocularis in carnivores in Razavi Khorasan province, Iran, using mitochondrial DNA. Plos Negl. Trop. Dis., 5(11): 1-8.

27. Gholami, I., Daryani, A., Sharif, M., Amouei, A. and Mobedi, I. (2011) Seroepidemiological survey of helminthic parasites of stray dogs in Sari city, Northern Iran. Pak. J. Biol Sci., 14(2): 133-137.

28. Carmena, D. and Cardona, G.A. (2013) Canine echinococcosis: Global epidemiology and genotypic diversity. Acta Trop., 128(3): 441-460.

29. Rokni, M. (2009) Echinococcosis/hydatidosis in Iran. Iran. J. Parasitol., 4(2): 1-16.

30. Kohansal, M.H., Nourian, A. and Bafandeh, S. (2015) Human cystic Echinococcosis in Zanjan area, Northwest Iran: A retrospective hospital based survey between 2007 and 2013. Iran. J. Public Health, 44(9): 1277-1282.

31. Hadighi, R., Mirhadi, F. and Rokni, M.B. (2003) Evaluation of a dot-ELISA for the serodiagnosis of human hydatid diseases. Pak. J. Med. Sci., 19(4): 268-271.

32. Lotfi, M. (1992) Diagnosis and treatment of hydatid cyst of the liver: Twenty years experience in Iran. Pak. J. Surg., 8(4): 109-114.

33. Borji, H., Emami, M., Maleki, M., Razmi, G., Mehrjerdi, H.K. and Moghaddas, E. (2012) Alveolar echinococcosis infection in a monkey (Ateles geoffroyi) in Mashhad, Iran. Iran. J. Public Health., 41(2): 111-116.

34. Torgerson, P.R., Keller, K., Magnotta, M. and Ragland, N. (2010) The global burden of alveolar echinococcosis. Plos Neglect. Trop. Dis., 4(6): 1-10.

35. Oksanen, A., Siles-Lucas, M., Karamon, J., Possenti, A., Conraths, F.J., Romig, T., Wysocki, P., Mannocci, A., Mipatrini, D., La Torre, G., Boufana, B. and Casulli, A. (2016) The geographical distribution and prevalence of Echinococcus multilocularis in animals in the European Union and adjacent countries: A systematic review and meta-analysis. Parasit. Vectors, 9(1): 1-23. 